\title{
CHANGE DETECTION AND MARITIME SITUATION AWARENESS IN THE CHANNEL AREA - FEASIBILITY OF SPACE BORNE SAR FOR MARITIME SITUATION AWARENESS.
}

\author{
Bert van den Broek, Eric den Breejen, Rob Dekker, Arthur Smith \\ Netherlands Organisation for Applied Scientific Research TNO, The Hague, The Netherlands \\ Bert.vandenbroek@tno.nl
}

\begin{abstract}
In this paper we have analyzed military and security requirements for surveillance. Using a data-set of wide swath SAR imagery for the English channel and high resolution SAR data for the Zeebrugge and Rotterdam harbour we have discussed if these requirements can be met by using this kind of data. The requirement to detect anomalous behaviour at open sea can be fulfilled for ships with sizes $>30$ meter if appropriate context information is available. Displacement of not too small vessels and preparatory activities for illegal trafficking can often be detected in high resolution imagery. However, details and detection of replacements of these objects cannot be obtained.
\end{abstract}

Index Terms - Maritime Situation Awareness, Military Requirements, SAR, Change Detection

\section{INTRODUCTION}

Maritime Security Operations are conducted from an international military as well as from a border security perspective. Current military operations are missions to act against piracy, illegal fishing, smuggling of people, and terrorism. Examples of ongoing military missions are Active Endeavour in the Mediterranean Sea, and Ocean Shield off the Horn of Africa. Security operations are mainly focused on illegal immigration towards Europe.

For NATO operations, detection and surveillance means that all vessels within the designated area should be tracked, identified, analyzed and considered for possible boarding, using all available sensors. Every contact determined to be a suspect vessel should be tracked persistently and considered to be a potential target for a takedown operation.

Since 2008, Europe has embedded most of its research and development of surveillance and information systems against illegal immigration in the EUROSUR programme. EUROSUR aims to establish a European Border Surveillance System to reinforce the control of its external border. Increasing situational awareness at the external borders and improving the reaction capabilities of national authorities surveying the borders is essential here.

Military as well as security operations make use of space borne observations as provided through different channels such as commercial service providers or the GMES (Global Monitoring for the Environment and Security) programme. In this paper, we evaluate the operational benefit of one of the most potential satellite sources for surveillance, i.e. satellite SAR imagery.

Table 1 and table 2 show the top-level maritime CONOPS requirements for military operations (table 1) and security operations (table 2). The CONOPS requirements for military operations are derived from the NATO ATP-71 [1].

The CONOPS requirements for security are derived from the Concept of Operations for GMES support to EUROSUR [2]. The first CONOPS requirement addresses the detection of preparatory activities of illegal vessel departures such as building of huts and skid roads at beaches or suspect truck or human activities in ports. The second CONOPS requirement aims to detect small vessels in ports and beaches with a size of typically $5 \mathrm{~m}$. The third requirement mentions the persistent tracking of larger vessels $(>15 \mathrm{~m})$ from the port of departure up to $80 \mathrm{~km}$ off the European border. Finally, the fourth requirement aims to detect suspect vessel behaviour of larger vessels up to $80 \mathrm{~km}$ off coast.

The military and security requirements are much the same in the sense that a detection capability for small vessels and anomalous behaviour of larger vessels are needed. The difference between the security and requirements for the military operations is that the area to be covered is a few orders of magnitude larger for the latter.

Given the requirements mentioned above we discuss here the following research topics for the space borne SAR data.

R1) Which ships can be detected at open sea?

R2) Can anomalies be detected and can the follow-on route be predicted?

R3) Can small vessels near harbours and coasts be detected?

R4) Can preparatory activities be detected indicated by vehicles, deposits and dwellings? 
Table 1: Maritime CONOPS requirements for military operations

\begin{tabular}{|c|c|c|c|c|}
\hline CONOPS requirements & Information & $\begin{array}{l}\text { Object } \\
\text { size }\end{array}$ & $\begin{array}{l}\text { Update } \\
\text { period }\end{array}$ & Area of interest \\
\hline $\begin{array}{l}\text { Detection of small vessels to } \\
1000 \mathrm{~km} \text { off coast }\end{array}$ & $\begin{array}{l}\text { Skiffs and DHOWS used for piracy and } \\
\text { illegal smuggling of people }\end{array}$ & $5-15 \mathrm{~m}$ & daily & $\begin{array}{l}2000 \mathrm{~km} \text { along } \\
\text { coastline }\end{array}$ \\
\hline $\begin{array}{l}\text { Indicate suspect large vessels } \\
\text { to } 1000 \mathrm{~km} \text { off coast }\end{array}$ & $\begin{array}{l}\text { Indicate suspect behaviour of illegal } \\
\text { fishing vessels against normal } \\
\text { background }\end{array}$ & $15-50 \mathrm{~m}$ & daily & $\begin{array}{l}2000 \mathrm{~km} \text { along } \\
\text { coastline }\end{array}$ \\
\hline
\end{tabular}

Table 2: Maritime CONOPS requirements for security operations

\begin{tabular}{|c|c|c|c|c|}
\hline CONOPS requirements & Information & $\begin{array}{l}\text { Object } \\
\text { size }\end{array}$ & $\begin{array}{l}\text { Update } \\
\text { period }\end{array}$ & Area of interest \\
\hline $\begin{array}{l}\text { Monitoring of } 3^{\text {rd }} \text { country } \\
\text { ports and beaches }\end{array}$ & $\begin{array}{l}\text { Preparatory activities for illegal } \\
\text { immigration vessel departures }\end{array}$ & $>3-5 \mathrm{~m}$ & 6 hours & $\begin{array}{l}5-10 \mathrm{~km} \text { per } \\
\text { location }\end{array}$ \\
\hline $\begin{array}{l}\text { Detection if vessels have left } \\
3^{\text {rd }} \text { country ports and beaches }\end{array}$ & Illegal immigration vessel departures & $>3-5 \mathrm{~m}$ & 6 hours & $2 \mathrm{~km}$ per location \\
\hline $\begin{array}{l}\text { Tracking of large vessels over } \\
\text { high seas }>80 \mathrm{~km} \text { from EU } \\
\text { coast }\end{array}$ & $\begin{array}{l}\text { Detect and recognize specific illegal } \\
\text { immigration vessel }\end{array}$ & $>15-30 \mathrm{~m}$ & daily & $\begin{array}{l}400 \mathrm{~km} \text { along } \\
\text { coastline }\end{array}$ \\
\hline $\begin{array}{l}\text { Indicate suspect large vessels } \\
>80 \mathrm{~km} \text { from EU coast }\end{array}$ & $\begin{array}{l}\text { Indicate suspect behaviour of illegal } \\
\text { immigration vessels against normal } \\
\text { background }\end{array}$ & $>15-30 \mathrm{~m}$ & hours & $\begin{array}{l}400 \mathrm{~km} \text { along } \\
\text { coastline }\end{array}$ \\
\hline
\end{tabular}

\section{REQUIREMENT ANALYSIS}

SAR data for this analysis were acquired in the context of the NATO RTO SET-145 working group on Geospatial Intelligence with high Resolution Spaceborne SAR Data. A large SAR data-set was available from the Cosmo-SkyMed, Radarsat and TerraSAR-X satellites. Both wide swath SAR imagery for the English Channel and coincident high resolution images for the Zeebrugge and Rotterdam Harbor area were available for analysis. Also coincident AIS data were collected using the Marinetraffic website (http: www.marinetraffic.com).

\subsection{Which ships can be detected at open sea (R1)?}

Ship detection at sea using SAR has already been proven to be quite feasible [4]. Detection depends on the sea clutter, polarization, incidence angle, and the size of the target. We may expect that vessels with dimensions in the order of the resolution and larger will be detected. Vessels with sizes smaller than the resolution size can be detected, when the sea clutter is low and when the vessel is not too 'stealthy', i.e. the radar cross should not be too low.

Indeed the ScanSAR narrow beam data (Cosmo-Skymed) showed that most of the commercial ships carrying AIS (sizes 80-200 meter) could be detected. Smaller vessels with sizes in the order of 30 meter, mostly tug and pilot vessels were also seen in the ScanSAR narrow beam image.

Detection of smaller vessels could not be inspected since they usually do not use AIS, but is generally not expected for wide swath images with resolutions of 30 meter or more.
2.2. Can anomalies be detected and can the follow-on route be predicted $(\mathrm{R} 2)$ ?

Anomalies can be defined as vessel behaviour that is not conform the common rule of practice, e.g. a ship that crosses a shipping lane, a vessel that approaches the coast where no harbour is present etc, or a vessel at a position where usually no ships are found. This kind of anomalies can often be derived from SAR vessel detections in combination with a nautical chart or statistical information that expresses the common rule of practice.

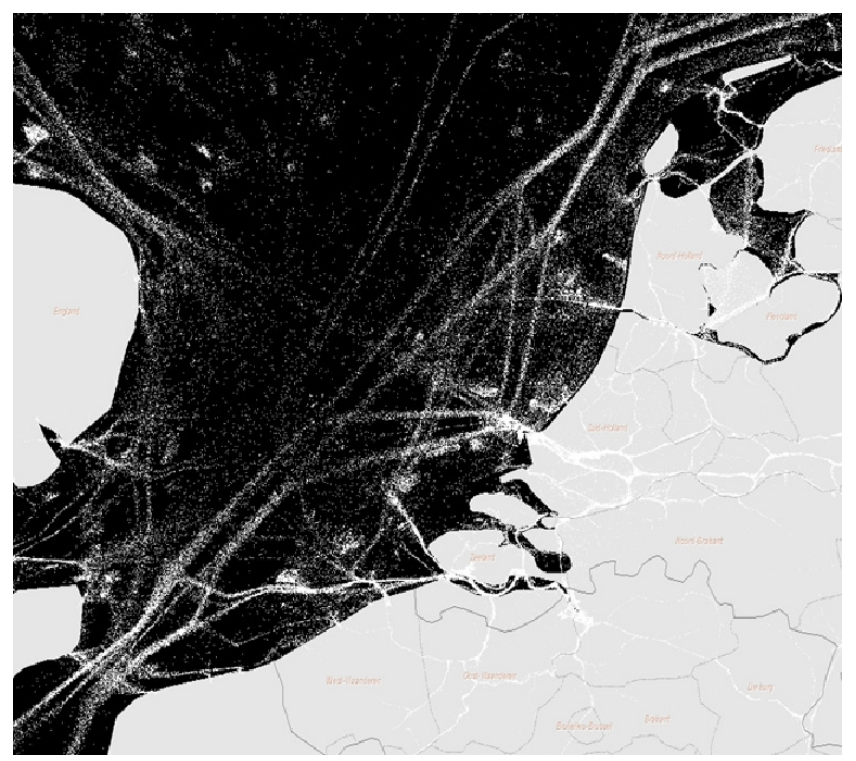

Figure 1: ship density image derived form AIS recordings in the Southern North Sea and English Channel 
Such statistical information can be derived from AIS data collected over a certain period. In figure 1 we show an AIS density picture on basis of continuous collection of AIS data during 6 weeks in May-July 2011. The figure clearly shows the main vessel lanes and anchorage areas in the Southern North Sea and English Channel. The density image can be analysed to obtain information about the vessel traffic system in the area. For example sea lane, vertices between the lanes, anchorage areas, entry and exit point near harbours can be derived [4]. For the sea lanes average vessel speed and information about the vessel types that use the lane can be obtained.

Anomaly detection can be obtained when SAR vessel detections are combined with this kind of information from the density picture. For the comparison also heading and vessel speed are to be derived for the SAR data, which is possible when the ship wake can be determined. Due the ship's motion a Doppler shift in azimuth direction is present in the SAR image, from which the speed can be estimated
[5], [6]. Accuracy depends on the resolution and the angle between the heading and satellite's orbit direction.

Also for prediction of the follow-on route such a density image can be used. Using the statistical information derived from the density picture future positions of a detected vessel can be made. Also possible arrival times in nearby harbours can be derived. Falchetti et al. [7] propose an algorithm for track prediction taking into account preferred ship routes as derived from the density picture and taking into account the coast lines.

\subsection{Can small vessels near harbours and coasts be detected (R3)?}

To detect small vessels (dimensions $<10$ meter) near the coast high resolution imagery is needed. We used high resolution (resolution 1 meter) spotlight SAR imagery from Cosmo-Skymed for the Zeebrugge and Rotterdam harbour areas.

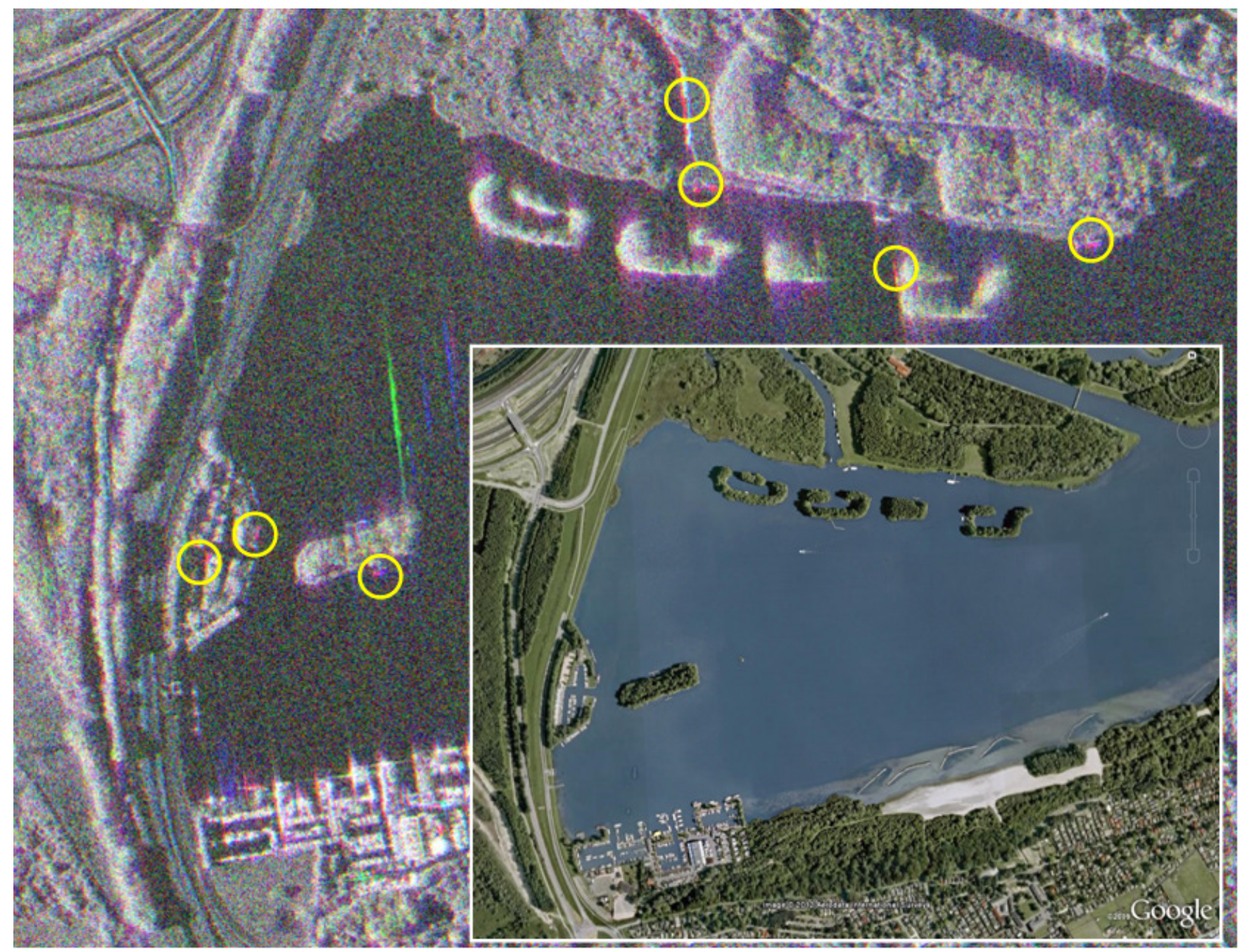

Figure 2: Cosmo-Skymed spotlight SAR imagery for three dates in the red, green and blue colours channel showing the arrival of recreational vessels (in yellow circles). For comparison GE visual imagery (inset) was used. 
Imagery was acquired for June 15, 16 and 192011 for the Zeebrugge area and June 29, 30 and July 32011 for the Rotterdam area. The SAR imagery for Zeebrugge has been collected at about 18:00 UT and for Rotterdam at 6:00 UT. After co-registration we inspected the combined imagery for changes by displaying the imagery for three dates in the red, green and blue colour bands (see figure 2). To be able to categorize the changes we used Google Earth (GE) visual imagery of the same areas. Both the Zeebrugge and the Rotterdam scene contain cargo harbours (large ships in the order of 100 meter) as well as marinas (small vessels $<10$ meter). The cargo areas clearly show ships which have arrived or left between the observation dates. The marinas are mostly occupied during all overpasses and no clear changes could be seen. For these small ships it is not possible to detect if ships have been replaced. The Rotterdam area also shows recreational landing stages where GE visual imagery shows vessels in the order of 10 meter. Changes indicate the arrival of such kind of vessels at the landing stags (see figure 2), indicating that arrival or departure of such kind vessels can be detected and interpreted when proper background knowledge is available.

\subsection{Can preparatory activities be detected indicated by vehicles, deposits and dwellings (R4)?}

Van den Broek at al. [8] showed that with high resolution Terrsar-X spotlight data it is possible to detect displacements of vehicles and deposits. Using the spotlight Cosmo-Skymed data of the Rotterdam cargo harbour areas we inspected a quay, where displacements of containers and trailers with sizes in the order of 10 meter are clearly visible confirming abovementioned Terra-SAR results.

Using the same kind of Cosmo-Symed data for the Zeebrugge area changes in car parking along the coast line could be seen. Changes in an area on the beach where catamarans (sizes of 2-3 meters) were stored could not be interpreted so that no conclusions could be drawn about replacements.

\section{SUMMARY AND CONCLUSIONS}

At open sea using ScanSAR images, ships with sizes $>30$ meter can generally be detected, while detection of small vessels is generally not possible (R1). Detection of anomalous behavior is sometimes possible when appropriate background information is available (R2). ScanSAR images with the resolutions considered here (30-50 meters) cover an area of $100-400 \mathrm{~km}$. A vessel with a speed of $10 \mathrm{kts}$ travels $400 \mathrm{~km}$ a day. Optimal revisit times are in the order of twice a day for Cosmo-Skymed [9]. Using data from several satellite operators, this would satisfy the security requirements for the area of interest, but is insufficient to fulfill the military requirements (area of interest $2000 \mathrm{~km}$ ).
This may improve in the future when larger constellations of SAR satellites can be used.

Small vessels (sizes in the order of 5-10 meter) can be monitored (R3) on basis of the detection of changes in high resolution SAR imagery (1 meter resolution). This implies that departure and arrival can be detected, but when anchorage locations are occupied at both observation dates, it cannot be concluded that a vessel has been replaced by another vessel. With respect to the requirements for preparatory activities (R4), (dis)appearance of objects and vehicles with sizes of 5 meter or larger can be detected on basis of change detection using the high resolution imagery. Again if at both dates an object is present detection of replacements is not well feasible. Changes due to (dis)appearance of objects $<5$ meter cannot be convincingly detected.

\section{REFERENCES}

[1] NATO ATP-71, "Allied Maritime Interdiction Operations", April 2005

[2] "Concept of Operations for GMES support to EUROSUR", version 1.4, July 2011,

http://ec.europa.eu/enterprise/policies/security/files/doc/conops_g mes_en.pdf

[3] D J. Weydahl, C. Brekke, P. Selvik, O. Helleren and R. Olsen, "Ship traffic monitoring using satellite SAR images in combination with AIS reports", Remote Sensing for Environmental Monitoring, GIS Applications, and Geology VII, Proc. of SPIE, Florence, Italy, Vol. 6749, 2007

[4] M. Vespe, K. Bryan, I. Visentini, "Maritime Anomaly Detection Based on Historical Trajectory Mining", Proceedings of NATO RTO SCI-247 Symposium on Port and Regional Maritime Security, Lerici, 21-23 May 2012

[5] R. K. Raney and R. A. Shuchman, "SAR mechanisms for imaging, waves," in Proc. 5th Can. Symp. Remote Sens., 1978, pp. 495-505.

[6] K. Eldhuset, "An automatic ship and ship wake detection system for spaceborne SAR images in coastal regions", IEEE Transactions on Geoscience and Remote Sensing, 34(4), 10101019, 1996

[7] S. Falchetti, M. Alvarez, T. Cokacar, H. Greidanus, M. Vespe, "Improving Cooperative Vessel Tracking for a Maritime Integrated Surveillance Platform", Proceedings of NATO RTO SCI-247 Symposium on Port and Regional Maritime Security, Lerici, 21-23 May 2012

[8] A.C. van den Broek, "Multi-temporal data analysis demonstration", Final report of NATO RTO SET-102 SAR Systems for Geospatial Intelligence, 2012, to be published.

[9] ASI, "Cosmo-SkyMed system description \& user guide", Agenzia Spaziale Italiana, Roma, Italy, http://eopi.asi.it, 2007. 